devices, leading to considerable cost savings in various industrial applications.

1. Fisher and Emerson, Control Valve Handbook, Fisher Control Internation, 2017, pp. 187-188, 5th edn.

2. Zakirnichnaya, M. M. and Kulsharipov, I. M., Wedge gate valves selecting essentials in pipeline systems designing based on Sci., 2017; doi:10.1088/1755-1315/87/8/082055.

3. Steele Jr, R., DeWall, K. G., Watkins, J. C., Russell, M. J. and Bramwell, D., Gate valve and motor-operator research findings, Division of Engineering Technology, Office of Nuclear Regulatory Research U.S. Nuclear Regulatory Commission, Washington, DC, USA, 1995; doi:10.2172/106407.

4. Sathe, N. J., Hinge, G. A. and Suryawanshi, V. S., Experimental results showing discharge variation in gate valve. Elixir Int. J., 2016, 93, 39819-39824, ISSN 2229-712x.

ACKNOWLEDGEMENT. We thank the Board of College and University Development at Pune University for funds and the Management of Bhivarabai Sawant College of Engineering and Research, Pune, for providing infrastructural facilities. permissible operation parameters. IOP Conf. Ser.: Earth Environ.

tive is to recover titanium-bearing minerals such as ilmenite and rutile from red sediment deposits of badlands in Odisha, India, by optimizing the operating parameters of single- and double-electrode HTS. We predict titanium-bearing minerals recovery as a function of feed rate, temperature and drum speed. The optimized response was validated against data derived from both HTS test works comprising (i) mineral grade, (ii) mineral recovery and (iii) process yield. The study describes the optimization procedure using RSM and MATLAB. RSM was used for optimizing the criteria for separation of titanium-bearing minerals by varying feed rate, temperature and drum speed. It was observed that factors like maximum yield \%, grade $\%$ and recovery $\%$ for ilmenite using doubleelectrode HTS method were better than singleelectrode HTS method. Thus, it can be concluded on the basis of overall performance from both experimental and predicted values, that the double-electrode HTS method is better than the single-electrode HTS method, particularly from the grade and recovery point of view.

Keywords: Badlands topography, high-tension separator, red sediments, single and double electrodes, titaniumbearing minerals.

\section{Optimization for single- and double-electrode high-tension separators using surface methodology to recover titanium minerals from Red Sediments, Odisha, India}

\author{
Asnani Chandru Kumar ${ }^{1, *}$, Satya Sai Srikant ${ }^{2}$, \\ Raghupatruni Bhima $\mathrm{Rao}^{3}$ and N. R. Mandre ${ }^{4}$ \\ ${ }^{1}$ Uranium Corporation of India Limited, Jaduguda Mines, \\ East Simghbhum, Jharkhand 832 102, India \\ ${ }^{2}$ SRM Institute of Science and Technology, Modinagar 201 204, India \\ ${ }^{3}$ CSIR-Institute of Minerals and Materials Technology, \\ Bhubaneswar 751013 , India \\ ${ }^{4}$ Department of Fuel and Mineral Engineering, Indian Institute of \\ Technology, Dhanbad 826 004, India
}

This study deals with the optimization of operating parameters of single- and double-electrode high tension electrostatic separators (HTS) using response surface methodology (RSM). The parametric optimization takes into account feed rate, temperature and drum speed as major operating variables. The objec-

*For correspondence. (e-mail: asnanick@gmail.com)
BADLANDS topography exists all along the east coast of India ${ }^{1}$. In general, these badlands are formed with red sediments which consist of placer minerals, including quartz, ilmenite, sillimanite, zircon, monazite, rutile and other minerals in small amounts. The general practice to recover heavy minerals involves scrubbing, desliming and gravity spirals. The heavy mineral concentrate output from the spiral operation is subjected to high-tension separation to recover ilmenite and rutile. However, the performance of the high-tension separator (HTS) depends on particle size, electrode position, drum speed, temperature of the feed and feed rate. In our experience, singlestage operation may not give high-grade titanium-bearing minerals at a higher recovery. Hence, it is necessary to optimize the process variables to recover maximum-grade titanium-bearing minerals using software to reduce the number of experiments for optimization of the process. The response surface methodology (RSM) with BoxBehnken design is one of the useful methods to optimize the process parameters. This method has already been applied for optimizing process parameters through RSM for grinding experiments of coal samples ${ }^{2}$ as well as for producing graphite concentrates ${ }^{3}$. An optimization model for separation of titanium-bearing minerals from beach sand minerals was also developed using $\mathrm{RSM}^{4-6}$.

This study aims to recover maximum-grade titaniumbearing minerals from red sediments using singleelectrode and double-electrode HTS. The experimental results were analysed using software like Design expert 6.0.6 (RSM), ANOVA and MATLAB 8.1. The optimum 


\section{RESEARCH COMMUNICATIONS}

Table 1. Design of experiments on recovery of ilmenite with single and double-electrode high tension electrostatic separator (HTS)

\begin{tabular}{|c|c|c|c|c|c|c|}
\hline \multirow[b]{2}{*}{ Run } & \multicolumn{3}{|c|}{ Single-electrode HTS method } & \multicolumn{3}{|c|}{ Double-electrode HTS method } \\
\hline & $\begin{array}{c}\text { Factor } \mathrm{A}: \\
\text { feed rate }(\mathrm{kg} / \mathrm{h})\end{array}$ & $\begin{array}{c}\text { Factor B: } \\
\text { temperature }\left({ }^{\circ} \mathrm{C}\right)\end{array}$ & $\begin{array}{c}\text { Factor } \mathrm{C}: \\
\text { roller speed }(\mathrm{RPM})\end{array}$ & $\begin{array}{c}\text { Factor } \mathrm{A}: \\
\text { feed rate }(\mathrm{kg} / \mathrm{h})\end{array}$ & $\begin{array}{c}\text { Factor } \mathrm{B}: \\
\text { temperature }\left({ }^{\circ} \mathrm{C}\right)\end{array}$ & $\begin{array}{c}\text { Factor } \mathrm{C}: \\
\text { roller speed }(\mathrm{RPM})\end{array}$ \\
\hline 1 & 15 & 100 & 140 & 25 & 110 & 200 \\
\hline 2 & 25 & 100 & 100 & 40 & 140 & 150 \\
\hline 3 & 15 & 200 & 40 & 25 & 110 & 150 \\
\hline 4 & 15 & 120 & 120 & 10 & 110 & 150 \\
\hline 5 & 15 & 140 & 140 & 25 & 140 & 150 \\
\hline 6 & 20 & 100 & 70 & 40 & 110 & 100 \\
\hline 7 & 20 & 100 & 140 & 25 & 110 & 100 \\
\hline 8 & 15 & 200 & 40 & 25 & 110 & 150 \\
\hline 9 & 20 & 140 & 50 & 25 & 110 & 100 \\
\hline 10 & 20 & 140 & 100 & 25 & 140 & 200 \\
\hline 11 & 20 & 140 & 120 & 25 & 140 & 150 \\
\hline 12 & 25 & 100 & 40 & 40 & 110 & 150 \\
\hline 13 & 25 & 100 & 50 & 25 & 140 & 100 \\
\hline 14 & 25 & 100 & 100 & 25 & 110 & 150 \\
\hline 15 & 25 & 100 & 120 & 25 & 110 & 100 \\
\hline 16 & 20 & 120 & 70 & 25 & 110 & 150 \\
\hline 17 & 20 & 120 & 140 & 25 & 140 & 150 \\
\hline 18 & 15 & 140 & 140 & 40 & 110 & 100 \\
\hline 19 & 20 & 120 & 140 & 25 & 110 & 150 \\
\hline
\end{tabular}

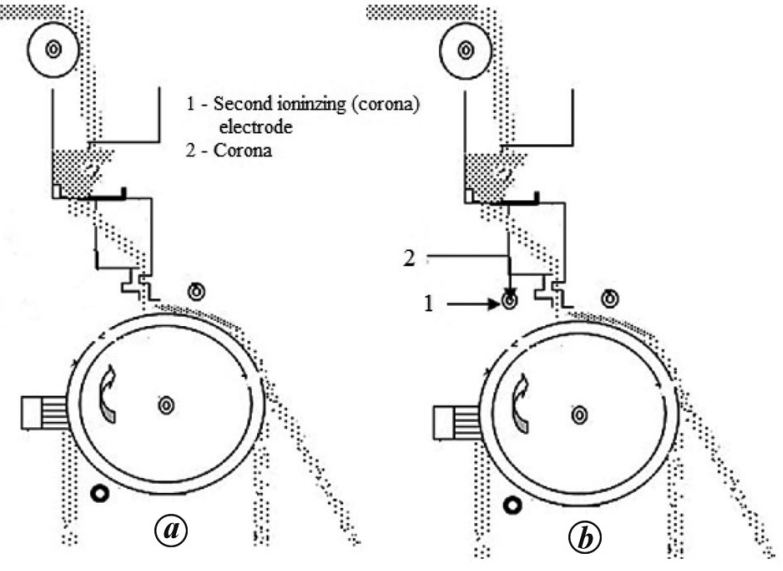

Figure 1. Design aspects of high-tension separators (HTS) with (a) single and $(\boldsymbol{b})$ double electrodes.

conditions obtained from experimental design and software were then compared.

Red sediment samples were collected from typical badlands topography of Kallipalli village, Ganjam district, Odisha, India, and deslimed using hydrocyclone. The sand was sent to a spiral gravity unit to recover total heavy minerals of $98 \%$ grade. The dried sand was used in HTS with single and double electrodes (Figure 1). Mineral grade was estimated by grain-counting method using standard binocular microscope.

It is desirable to analyse the effect of operational parameters for optimization of output responses, i.e. grade and recovery of ilmenite, obtained from red sediments of badlands topography with single-electrode and doubleelectrode HTS methods. There were mainly three signifi- cant operational parameters, i.e. feed rate, temperature and roller speed. The results were evaluated using the Box-Behnken factorial design ${ }^{1,2}$. Responses like grade and recovery efficiency of the process were optimized using the experimental design as well as ANOVA, and have been presented as $3 \mathrm{D}$ response surface graphs. Table 1 shows details of the experimental design of HTS for both single and double-electrode methods, with the operating variables feed rate, temperature and roller speed (RPM) maintained at different levels.

The results were compared as shown in Table 2, to recover ilmenite from red sediment minerals. These results were analysed using Design Expert - ANOVA.

Figures $2 a, 3 a$ and $4 a$ show 3D response surface plots, which describe the effect of yield, grade and recovery respectively, with change in roller speed using the double-electrode HTS method. Figures $2 b, 3 b$ and $4 b$ shows $3 \mathrm{D}$ response surface plots using singleelectrode HTS method for yield, grade and recovery respectively.

The ANOVA equation for yield \% of ilmenite using double electrode HTS method along with $R^{2}$ is

$$
\begin{aligned}
& \text { Yield } \%=74.03-0.0008 A-1.27 B-0.7 C-0.82 C^{2} \\
& \quad+3.01 A B+1.39 B C, \\
& R^{2}=69.27 \% .
\end{aligned}
$$

The yield $\%$ of ilmenite using single-electrode HTS method is

$$
\begin{aligned}
& \text { Yield } \%=74+6.62 A-19.72 B+6.05 C+18.12 B^{2} \\
& \quad-7.58 C^{2}-5.21 A B, \\
& R^{2}=67.39 \% .
\end{aligned}
$$


RESEARCH COMMUNICATIONS

Table 2. Ilmenite recovery using single- and double-electrode HTS methods

\begin{tabular}{|c|c|c|c|c|c|c|}
\hline \multirow[b]{2}{*}{ Run } & \multicolumn{3}{|c|}{ Single-electrode HTS method } & \multicolumn{3}{|c|}{ Double-electrode HTS method } \\
\hline & Yield \% & Grade $\%$ & Recovery \% & Yield \% & Grade $\%$ & Recovery $\%$ \\
\hline 1 & 73.19 & 96.12 & 85.69 & 75 & 97.71 & 89.26 \\
\hline 2 & 75.77 & 97.44 & 89.93 & 73.74 & 99.09 & 89 \\
\hline 3 & 75 & 97.71 & 89.26 & 73.2 & 98.73 & 88.03 \\
\hline 4 & 73 & 97 & 86.25 & 73.74 & 99.09 & 89 \\
\hline 5 & 73.2 & 98.73 & 88.03 & 76.8 & 99.67 & 93.24 \\
\hline 6 & 73.74 & 99.09 & 89.00 & 75 & 97.71 & 89.26 \\
\hline 7 & 76.8 & 99.67 & 93.24 & 73.91 & 99.68 & 89.74 \\
\hline 8 & 75 & 97.71 & 89.26 & 71.9 & 95.21 & 83.38 \\
\hline 9 & 73.91 & 99.68 & 89.74 & 73.79 & 98.52 & 88.55 \\
\hline 10 & 71.9 & 95.21 & 83.38 & 73.74 & 99.09 & 89 \\
\hline 11 & 73.79 & 98.52 & 88.55 & 70.51 & 98.25 & 84.38 \\
\hline 12 & 71.93 & 98.01 & 85.87 & 72.2 & 99.18 & 87.22 \\
\hline 13 & 70.51 & 98.25 & 84.38 & 72.64 & 99.7 & 88.21 \\
\hline 14 & 72.2 & 99.18 & 87.22 & 76.8 & 99.67 & 93.24 \\
\hline 15 & 72.64 & 99.7 & 88.21 & 72.77 & 99.22 & 87.94 \\
\hline 16 & 75.92 & 98.56 & 91.14 & 73.74 & 99.09 & 89 \\
\hline 17 & 72.77 & 99.22 & 87.94 & 75 & 97.71 & 89.26 \\
\hline 18 & 75.25 & 98.44 & 90.23 & 76.8 & 99.67 & 93.24 \\
\hline 19 & 75 & 97.71 & 89.26 & 75 & 97.71 & 89.26 \\
\hline
\end{tabular}
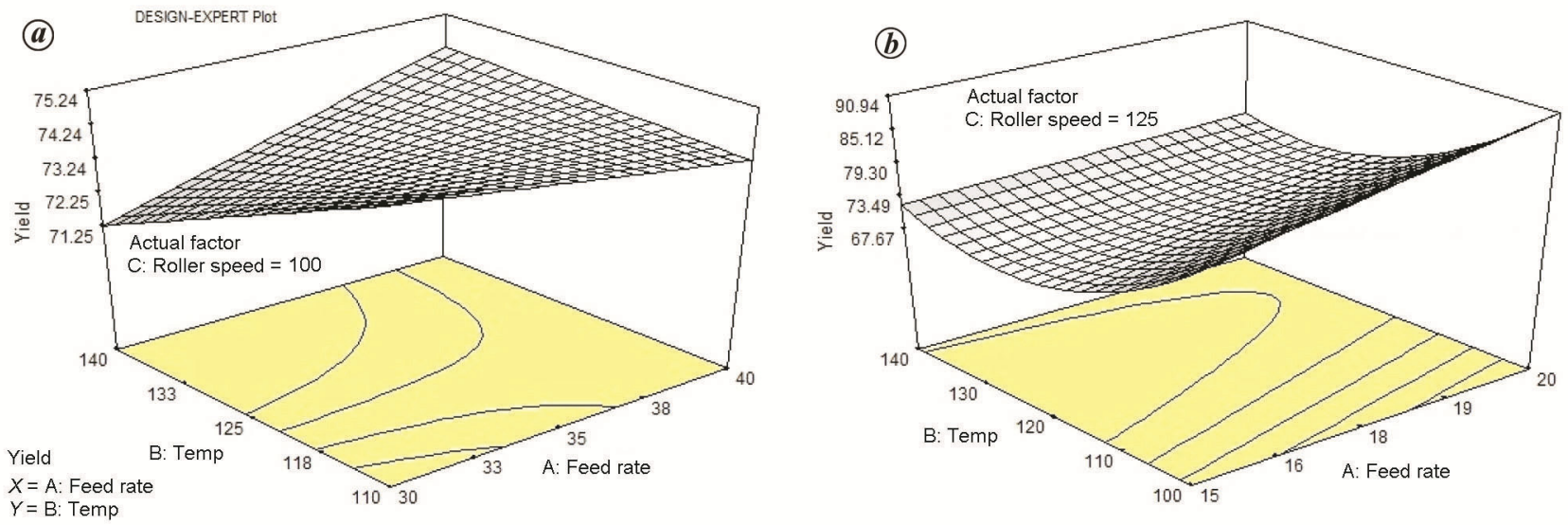

Figure 2. Yield \% of $(\boldsymbol{a})$ double-electrode HTS and $(\boldsymbol{b})$ single-electrode HTS.

Similarly, grade $\%$ of ilmenite using double-electrode HTS method along with $R^{2}$ is

$$
\begin{aligned}
& \text { Grade } \%=98.04-0.61 A-0.041 B-1.88 C-0.94 C^{2} \\
& \quad-0.31 A B+0.36 B C \\
& R^{2}=99.68 \% .
\end{aligned}
$$

Grade \% of ilmenite using single-electrode HTS method is

$$
\begin{aligned}
& \text { Grade } \%=96.57-1.62 A+6.07 B+0.72 C-5.6 B^{2} \\
& \quad+0.88 C^{2}+0.78 A B \\
& R^{2}=97.42 \%
\end{aligned}
$$

It is observed that maximum yield \% to recover ilmenite using double-electrode HTS method $\left(R^{2}=69.27 \%\right)$ is better than single-electrode HTS method $\left(R^{2}=67.39 \%\right)$. Also, grade \% with the former method $\left(R^{2}=99.68 \%\right)$ is better than the method $\left(R^{2}=97.42 \%\right)$. Recovery \% using the double-electrode HTS method $\left(R^{2}=97.09 \%\right)$ is also better than the single-electrode HTS method $\left(R^{2}=\right.$ $92.5 \%$ ). Table 3 shows the optimized experimental and predicted values using both method to recover ilmenite.

Table 3 shows a close match between experimental and predicted data over most of the operational range. On the basis of overall performance from both experimental and predicted values, the double-electrode HTS method is found to be better than the single-electrode HTS method, particularly with respect to grade and recovery.

The following conclusions are drawn from the experimental and optimization studies carried out on red sediments for the recovery of titanium-bearing minerals, 

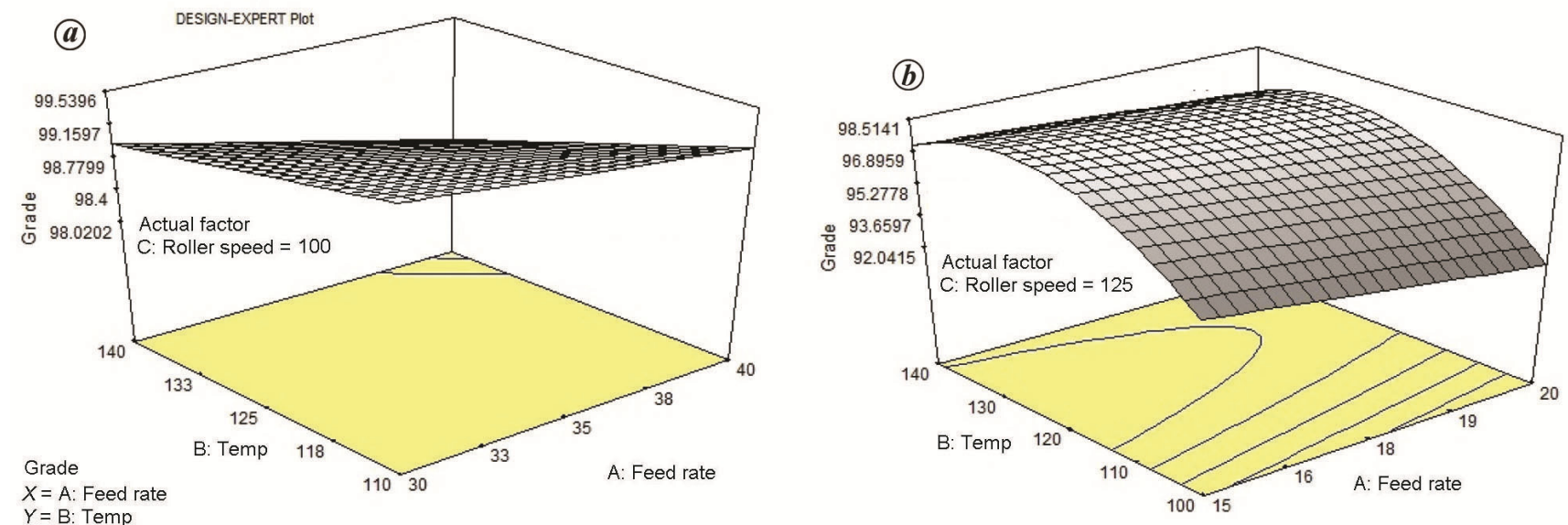

Figure 3. Grade \% of (a) double-electrode HTS and (b) single-electrode HTS.
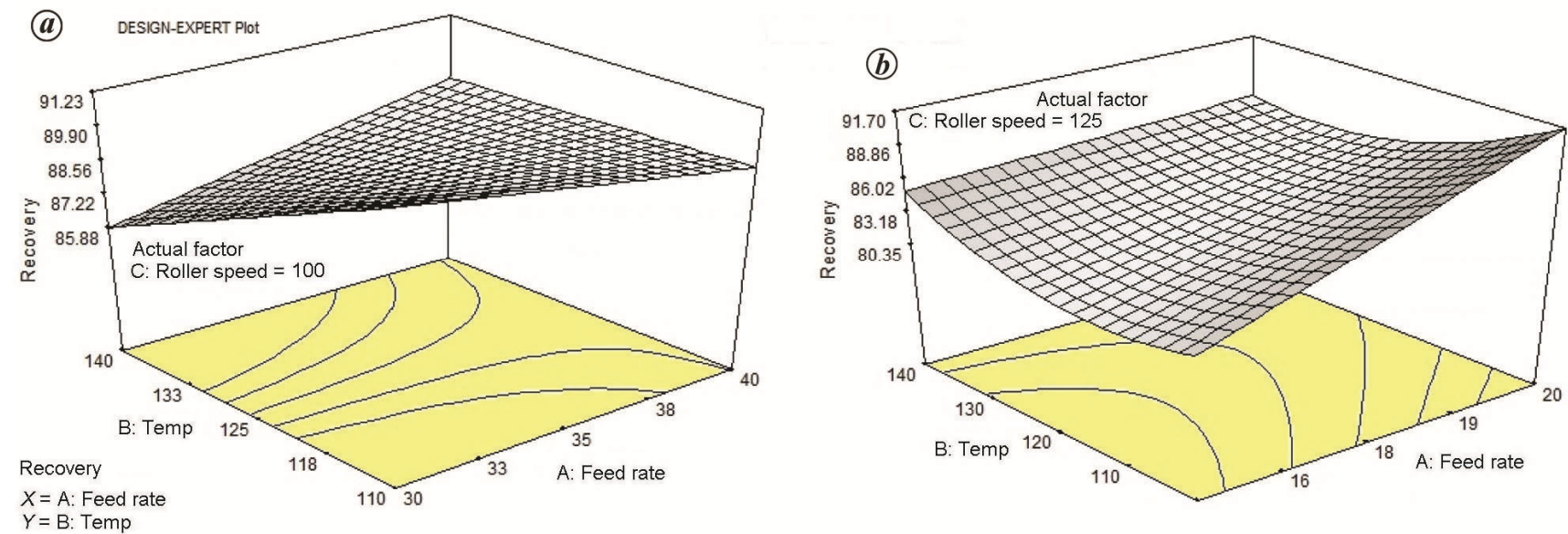

Figure 4. Recovery \% of (a) double-electrode HTS and (b) single-electrode HTS.

Table 3. Optimized experimental and predicted response surface methodology (RSM) values using single- and double-electrode HTS methods

\begin{tabular}{lccccc}
\hline Methods & \multicolumn{2}{c}{ Single-electrode HTS } & & \multicolumn{2}{c}{ Double-electrode HTS } \\
\cline { 2 - 3 } \cline { 5 - 6 } Parameters & Experimental & Predicted value with RSM & & Experimental & Predicted value with RSM \\
\hline A: Feed rate $(\mathrm{kg} / \mathrm{h})$ & 20 & 20 & 140 & 25 & 30 \\
B: Temperature $\left({ }^{\circ} \mathrm{C}\right)$ & 140 & 120 & 73.8 & 110 & 110 \\
C: Rotation speed $(\mathrm{RPM})$ & 72.8 & 96.2 & & 700 & 700 \\
Response 1: Yield \% & 96.5 & 86.4 & & 99.67 & 99.24 \\
Response 2: Grade \% & 85.6 & & 93.24 & 91.23 \\
Response 3: Recovery \% & & & & & \\
\hline
\end{tabular}

including ilmenite and rutile by optimizing different parameters of single- and double-electrode HTS.

- Red sediments of badlands topography contain placer heavy minerals, including ilmenite, rutile, sillimanite, zircon, monazite, traces of garnet, etc.

- The three factorial central composite design with RSM could be employed successfully for modelling HTS. Different equations have been developed by varying three parameters, viz. feed rate, temperature and drum speed.

- For a better understanding of the variables of HTS on grade, recovery and yield (process and equipment) in both methods, the predicted model values could be presented as 3D response surface graphs.

- It is clear from this study that all the three responses, i.e. grade, recovery and yield could be optimized using RSM optimization techniques with application 
of ANOVA and MATLAB by which plant performance could be improved.

- The results show that by changing one input variable, i.e. roller speed, and keeping temperature and feed rate as constant for both double-electrode as well as single-electrode HTS methods, maximum yield \% to recover ilmenite using the former method $\left(R^{2}=69.27 \%\right)$ is better than the better method $\left(R^{2}=67.39 \%\right)$.

- Grade \% using double-electrode HTS method $\left(R^{2}=\right.$ $99.68 \%)$ is better than single-electrode HTS method $\left(R^{2}=97.42 \%\right)$. Mainly, recovery \% using the former method $\left(R^{2}=97.09 \%\right)$ is better than the latter method $\left(R^{2}=92.5 \%\right)$.

- Thus it can be concluded on the basis of the overall performance from both experimental and predicted values, that the double-electrode HTS method is better than the single-electrode HTS method, particularly with respect to grade and recovery.

1. Aslan, N. and Cebeci, Y., Application of Box-Behnken design and response surface methodology for modelling of some Turkish coals. Fuel Technol., 2007, 86, 769-776.

2. Laxmi, T. and Bhima, R B., Badland topography of coastal belt sediment deposits of India: a potential resource for industrial minerals. Mines Miner. Rep., 2010, 3, 12-18.

3. Aslan, N., Cifci, F. and Yan, D., Optimization of process parameters for producing graphite concentrate using response surface methodology. Sep. Purif. Technol., 2008, 59, 9-16.

4. Laxmi, T., Aslan, N. and Bhima, R. B., Optimization of some parameters of high tension roll separator to recover titaniferrous placer minerals. Int. J. Eng. Appl. Sci., 2012, 4, 9-25.

5. Laxmi, T. and Bhima, R. B., Studies on optimization of rougher wet high intensity magnetic separator to recover ilmenite from placer heavy minerals. Turk. J. Eng. Sci. Technol., 2015, 1, 1-10.

6. Tripathy, S. K., Ramamuthy, Y. and Raghu, K. C., Modeling of high-tension roll separator for separation of titanium bearing minerals. Powder Technol., 2010, 201, 181-186.

ACKNOWLEDGEMENTS. We thank CSIR-Institute of Minerals and Materials Technology, Bhubaneswar for permission to carry out this study.

Received 9 November 2018; accepted 26 June 2020

doi: $10.18520 / \mathrm{cs} / \mathrm{v} 119 / \mathrm{i} 4 / 695-699$

\section{Parasitism ecology of sandalwood (Santalum album $\mathbf{L}$.) for commercial production in the semi-arid tropics}

\author{
Doddabasawa $^{1, *}$, B. M. Chittapur ${ }^{2}$ and \\ R. Lokesh ${ }^{1}$ \\ ${ }^{1}$ College of Agriculture, Bheemarayanagudi, Yadgir 585 287, India \\ ${ }^{2}$ Directorate of Extension, University of Agricultural Sciences, \\ Raichur 584 102, India
}

Successful establishment of a sandalwood plantation is rather difficult due to its complex parasitism ecology and unique silvics of the host species. The present study was therefore undertaken to understand the parasitism ecology of sandalwood under natural population in the semi-arid tropics, covering the northeastern dry zone of Karnataka, India. Sandalwood was found to parasitize on nine different tree species belonging to four families dominated by Leguminosae (six tree species), and the maximum associations occurred with Acacia nilotica. Sandalwood tree requires long-term suitable host not only for mineral nutrients replenishment, but also for water supplementation to maintain plant water potential and minimal composition in above-ground parts apart from sufficient sunlight. Therefore, selection of suitable host assumes significance. $A$. nilotica and $C$ siamea are preferred hosts, particularly at planting distance of $2.5 \mathrm{~m}$ in the semi-arid tropics of India. A planting geometry of $6 \mathrm{~m} \times 6 \mathrm{~m}$ or $5 \mathrm{~m} \times 5 \mathrm{~m}$ with sandalwood between the host plants at 2.5 to $3.0 \mathrm{~m}$ is ideal.

Keywords: Ecology, host species, parasitism, sandalwood, semi-arid tropics.

SANDALWOOD (Santalum album L.) belonging to the family Santalaceae is an evergreen, small to medium-sized hemi-root parasitic tree species endemic to peninsular India ${ }^{1}$. It is one of the precious and highly valued tree species known for its fragrant heart wood and oil ${ }^{2,3}$. The oil is extensively used in highly valued perfumery, cosmetics and medicine. Sandalwood also has religious significance and the wood is used in the handicrafts industry ${ }^{4}$.

India is the major exporter of East Indian sandalwood and accounts for $90 \%$ of the total global production. However, production has decreased from 4000 to $500 \mathrm{t} / \mathrm{yr}$ in the country, whereas the global demand for sandalwood is between 5000 and $6000 \mathrm{t} / \mathrm{yr}$ (ref. 5). This gap has increased the price of sandalwood in the national and international markets by several folds. The decreasing production in India is mainly attributed to factors like illicit felling, forest fires, spike disease, poor natural regeneration, high demand in both national and international markets, and indiscriminate harvesting of trees by uprooting as oil is present in both heart wood and roots ${ }^{1,6,7}$.

*For correspondence. (e-mail: dkpati12020@gmail.com) 